\title{
The Effect of Alkalosis on Hypoxia-Induced Pulmonary Vasoconstriction in Lungs of Newborn Rabbits
}

\author{
CANDICE D. FIKE AND THOMAS N. HANSEN \\ Baylor College of Medicine, Department of Pediatrics, One Baylor Plaza, Houston, Texas 77030
}

\begin{abstract}
The purpose of this study was to determine whether metabolic and respiratory alkalosis reduce hypoxia-induced pulmonary vasoconstriction in lungs of newborn rabbits. To accomplish this, we isolated and perfused with blood the lungs from 33 newborn rabbits, 3-14 d old. In all pairs of lungs, we first measured the magnitude of hypoxia-induced pulmonary vasoconstriction at a $\mathrm{pH}$ of 7.30-7.42. We then measured the effect of alkalosis on the magnitude of hypoxic pulmonary vasoconstruction by following one of two different sequences of exposure to hypoxia and alkalosis. For the first sequence, we exposed 13 lungs to hypoxia, and during the hypoxic exposure we either decreased the inspired $\mathrm{P}_{\mathrm{CO}_{2}}$ (respiratory alkalosis, $n$ $=8$ ) or infused $\mathrm{NaHCO}_{3}$ (metabolic alkalosis, $n=5$ ) to achieve a $\mathrm{pH}$ of 7.50-7.65. For the second sequence, we first decreased the inspired $\mathrm{P}_{\mathrm{CO}_{2}}(n=9)$ or infused Na$\mathrm{HCO}_{3}(n=11)$ to achieve a pH of 7.50-7.65 and then exposed the lungs to hypoxia. We found that hypoxic pulmonary vasoconstriction was reduced by either respiratory or metabolic alkalosis, when alkalosis was induced during hypoxia. When respiratory or metabolic alkalosis was induced before hypoxia, the magnitude of hypoxiainduced pulmonary vasoconstriction was the same as at the normal $\mathrm{pH}$. We conclude that both metabolic and respiratory alkalosis reduce ongoing hypoxic pulmonary vasoconstriction in lungs of newborn rabbits. However, neither mode of alkalosis blunts pulmonary vasoconstriction in response to subsequent exposures to hypoxia. (Pediatr Res 25:383-388, 1989)
\end{abstract}

Abbreviations

$\mathrm{Pi}_{\mathrm{O}_{2}}$, inspired $\mathrm{P}_{\mathrm{O}_{2}}$ $\mathrm{Pi}_{\mathrm{CO}_{2}}$, inspired $\mathrm{P}_{\mathrm{CO}_{2}}$

Alveolar hypoxia has been demonstrated to cause pulmonary vasoconstriction in lungs of both mature $(1-10)$ and newborn $(4,9,11-16)$ animals. The influence of changing $\mathrm{pH}$ on hypoxiainduced pulmonary vasoconstriction has, however, been examined primarily in lungs of mature animals $(1,3,6-8,10)$. In particular, only a few studies have evaluated the influence of alkalosis on hypoxia-induced pulmonary vasoconstriction in lungs of newborn animals (13-15), and the results of these studies have been variable. Yet, alkalosis, produced primarily by mechanical hyperventilation, is widely used with the intent to reduce pulmonary vasoconstriction in newborns with the syndrome of persistent pulmonary hypertension $(17,18)$.

The purpose of this study was to determine whether or not

Received August 1, 1988: accepted November 22, 1988

Correspondence to Candice D. Fike. M.D., Baylor College of Medicine, One Baylor Plaza, Houston, TX 77030. alkalosis reduces hypoxia-induced pulmonary vasoconstriction in lungs of a newborn animal. We also wanted to determine if metabolic and respiratory-induced alkalosis have similar effects on hypoxic pulmonary vaosconstriction. Finally, we wondered if inducing alkalosis during versus before exposure to hypoxia would produce different results. To accomplish these goals, we first measured the magnitude of hypoxia-induced pulmonary vasoconstriction at a $\mathrm{pH}$ of 7.30-7.42 in isolated, perfused lungs of newborn rabbits. Next, in some lungs we repeated the hypoxic challenge and during hypoxia induced respiratory or metabolic alkalosis. In other lungs, we induced respiratory or metabolic alkalosis and then repeated the hypoxic challenge. We found that both metabolic and respiratory alkalosis decreased the magnitude of hypoxia-induced pulmonary vasoconstriction when alkalosis was induced during the hypoxic challenge. In contrast, when either mode of alkalosis was induced before hypoxia, pulmonary arterial vasoconstriction was not decreased. We conclude that respiratory and metabolic alkalosis have similar effects on hypoxia-induced pulmonary vasoconstriction in lungs of newborn rabbits. Both types of alkalosis reduce ongoing hypoxic pulmonary vasoconstriction, and neither diminishes vasoconstriction in response to subsequent hypoxia.

\section{MATERIALS AND METHODS}

Surgical preparation. We anesthetized 33 New Zealand White newborn rabbit pups, ages 3-14 d, wt $148 \pm 52$ g, with sodium pentobarbital ( $30-50 \mathrm{mg} / \mathrm{kg}$ body wt) injected intraperitoneally. We inserted a cannula into the trachea of each rabbit and ventilated its lungs using a piston-type rodent respirator (Harvard Apparatus Inc., South Natick, MA) at a tidal vol of 3-3.5 mL, a rate of 60 breaths/min, and an end expiratory pressure of $1-2$ $\mathrm{cm} \mathrm{H}_{2} \mathrm{O}$. The gases used for ventilation were premixed in mylar bags and the $\mathrm{P}_{\mathrm{O}_{2}}$ and $\mathrm{P}_{\mathrm{CO}_{2}}$ of each mixture measured. The initial $\mathrm{Pi}_{\mathrm{O}_{2}}$ was 150 torr, and the $\mathrm{Pi}_{\mathrm{CO}_{2}}$ was 38-42 torr.

After opening the chest wall by midline sternotomy, we injected $200 \mathrm{IU}$ of heparin into the left ventricle. We then ligated the ductus arteriosus and placed a fluid-filled catheter into the pulmonary artery through an incision in the right ventricle. Through an incision in the tip of the left ventricle, we manipulated a catheter through the mitral valve so that it fit snugly into the left atrium without suturing. Next, we bluntly dissected the entire thoracic cage away from the rabbit by severing the clavicles and spinal column above and below the chest cavity. Finally, we suspended the thoracic cage from the endotracheal tube and connected the lungs to the perfusion circuit described below.

Perfusion circuit. The perfusion circuit was filled with the perfusate which consisted of a mixture of equal parts of heparinized blood (10-20 IU $/ \mathrm{mL})$ and physiologic salt-albumin solution. The blood was obtained fresh daily from adult female donor rabbits, and the physiologic salt-albumin solution was prepared by mixing $50 \mathrm{~mL}$ of a physiologic salt solution (8) with $1.5 \mathrm{~g}$ bovine albumin and $0.5 \mathrm{~g}$ dextrose. The hematocrit of the perfusate was $19-21 \%$. 
The perfusate was pumped by a rotary pump (Masterflex, Cole-Palmer Co., Chicago, IL) from a reservoir through a bubble trap and blood filter (Hemo-nate Int. Inc., San Antonio, TX) into the pulmonary arterial catheter, through the lungs into the left atrial catheter and was then allowed to drip back into the reservoir. The perfusate was maintained at a temperature 37.5$39^{\circ} \mathrm{C}$ by suspending the reservoir in a water bath. The entire circuit, with the exception of the rotary pump, was enclosed in an isolette (Air Shields Inc., Hatboro, PA).

Pulmonary arterial pressure was measured continuously by a strain gauge transducer (P 23 Db, Gould Instruments, Hato Rey, PR), and airway pressure was measured continuously by a differential pressure transducer (PM 131 TC, Gould Instruments). The 0 reference for the pulmonary arterial pressure was the level of the left atrium and the 0 reference for the airway pressure was atmospheric. The outputs of the pressure transducers were recorded on a polygraph recorder (Grass Model 5, Grass Instruments, Quincy, MA). The end of the left atrial catheter was exposed to atmospheric pressure at the base of the lungs so that the lungs were perfused under zone 2 conditions (19).

Protocols. After connection to the perfusion circuit, the lungs were perfused for $30-45 \mathrm{~min}$ to achieve a steady baseline pulmonary arterial pressure, and the $\mathrm{pH}$ of the perfusate was adjusted to 7.30-7.42 if necessary by adding a small amount of $\mathrm{NaHCO}_{3}$ to the perfusate. Throughout all studies, the perfusion flow rate was maintained constant at $0.07 \mathrm{~mL} / \mathrm{g}$ body $\mathrm{wt} / \mathrm{min}$, and left atrial pressure was maintained constant at $0 \mathrm{~cm} \mathrm{H}_{2} \mathrm{O}$.

In all 33 pairs of lungs, we first measured the change in pulmonary arterial pressure in response to ventilation with a hypoxic gas mixture $\left(\mathrm{Pi}_{\mathrm{O}_{2}}=0\right.$ torr, $\mathrm{Pi}_{\mathrm{CO}_{2}}=38-42$ torr $)$ at a normal $\mathrm{pH}(\mathrm{pH}=7.30-7.42)$. Each challenge lasted 6 min and was followed by a 6-min recovery period of ventilation with a normoxic gas mixture ( $\mathrm{Pi}_{\mathrm{O}_{2}}=150$ torr, $\mathrm{Pi}_{\mathrm{CO}_{2}}=38-42$ torr). The time periods and gas mixtures were chosen because in a previous study using isolated lungs of newborn rabbits we demonstrated that 1 ) pulmonary arterial pressure increased and reached a plateau within 6 min of ventilation with an hypoxic gas mixture, 2) the maximal pulmonary arterial pressor response was obtained with an inspired $\mathrm{P}_{\mathrm{O}_{2}}$ of 0 torr, and 3) pulmonary arterial pressure responses to 6-min exposures of hypoxia were reproducible for up to $21 / 2-3 \mathrm{~h}$ of perfusion (11). After a consistent response of the pulmonary arterial pressure to alveolar hypoxia was obtained at a normal $\mathrm{pH}$, one of the following two sequences of exposure to hypoxia and alkalosis was randomly selected.

In the first sequence, respiratory or metabolic alkalosis was induced during hypoxia. For the respiratory alkalosis experiments, we ventilated the lungs from eight newborn rabbit pups with the hypoxic, normocapnic gas mixture $\left(\mathrm{Pi}_{\mathrm{O}_{2}}=0\right.$ torr, $\mathrm{Pi}_{\mathrm{CO}_{2}}$ $=38-42$ torr) for $6 \mathrm{~min}$. Next, we ventilated the lungs for $4-6$ min with a hypoxic, hypocapnic gas mixture $\left(\mathrm{Pi}_{\mathrm{O}_{2}}=0\right.$ torr, $\mathrm{Pi}_{\mathrm{CO}_{2}}$ $=15-20$ torr). Then the lungs were ventilated for a 6 -min recovery period with a normoxic, hypocapnic mixture $\left(\mathrm{Pi}_{\mathrm{O}_{2}}=\right.$ 150 torr, $\mathrm{Pi}_{\mathrm{CO}_{2}}=15-20$ torr. For the metabolic alkalosis experiments, we ventilated five other lungs with the hypoxic mixture $\left(\mathrm{Pi}_{\mathrm{O}_{2}}=0\right.$ torr, $\mathrm{Pi}_{\mathrm{CO}_{2}}=38-42$ torr $)$ for $6 \mathrm{~min}$. Next, we slowly added $\mathrm{NaHCO}_{3}$ to the perfusate while continuing to ventilate the lungs with the hypoxic mixture for an additional 4-6 min. Then we ventilated the lungs for a 6-min recovery period with the normoxic gas mixture ( $\mathrm{Pi}_{\mathrm{O}_{2}}=150$ torr, $\mathrm{Pi}_{\mathrm{CO}_{2}}=38-42$ torr $)$. Figure 1 illustrates a typical experiment in which metabolic alkalosis was induced during hypoxia.

In the second sequence, respiratory or metabolic alkalosis was induced before hypoxia. For the respiratory alkalosis experiments, we ventilated the lungs of nine other newborn rabbit pups with a normoxic, hypocapnic gas mixture $\left(\mathrm{Pi}_{\mathrm{O}_{2}}=150\right.$ torr, $\mathrm{Pi}_{\mathrm{CO}_{2}}$ $=15-20$ torr) for $10-15 \mathrm{~min}$. We then ventilated the lungs for 6 min with a hypoxic, hypocapnic gas mixture $\left(\mathrm{Pi}_{\mathrm{O}_{2}}=0\right.$ torr, $\mathrm{Pi}_{\mathrm{CO}_{2}}$ $=15-20$ torr), followed by a 6 -min recovery period of ventilation with the normoxic, hypocapnic gas mixture $\left(\mathrm{Pi}_{\mathrm{O}_{2}}=150\right.$ torr, $\mathrm{Pi}_{\mathrm{CO}_{2}}=15-20$ torr). For the metabolic alkalosis experiments, we ventilated the lungs of 11 other newborn rabbit pups with the normoxic gas mixture ( $\mathrm{Pi}_{\mathrm{O}_{2}}=150$ torr, $\mathrm{Pi}_{\mathrm{CO}_{2}}=38-42$ torr) for 6 min. We then slowly added $\mathrm{NaHCO}_{3}$ to the perfusate until an alkalotic $\mathrm{pH}$ of 7.50-7.65 was reached; we then waited 10-15 min to ensure a stable pulmonary arterial pressure. Next, we ventilated the lungs for $6 \mathrm{~min}$ with the hypoxic gas mixture $\left(\mathrm{Pi}_{\mathrm{O}_{2}}\right.$ $=0$ torr, $\mathrm{Pi}_{\mathrm{CO}_{2}}=38-42$ torr), followed by ventilation for a 6 -min recovery period with the normoxic mixture $\left(\mathrm{Pi}_{\mathrm{O}_{2}}=150\right.$ torr,

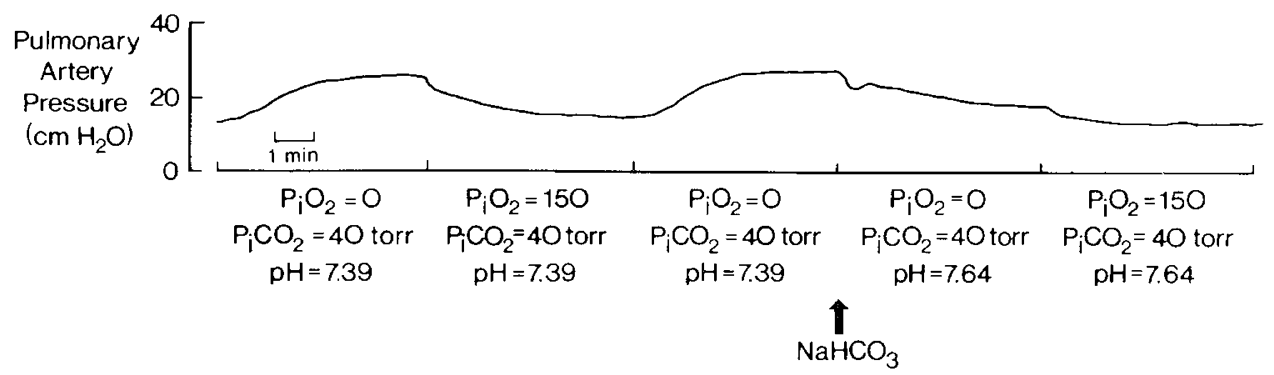

Fig. 1. Typical experiment in which metabolic alkalosis was induced during hypoxia. Pulmonary arterial pressure increased during hypoxic challenge at $\mathrm{pH}=7.39$ and then decreased when $\mathrm{NaHCO}_{3}$ was infused (arrow).

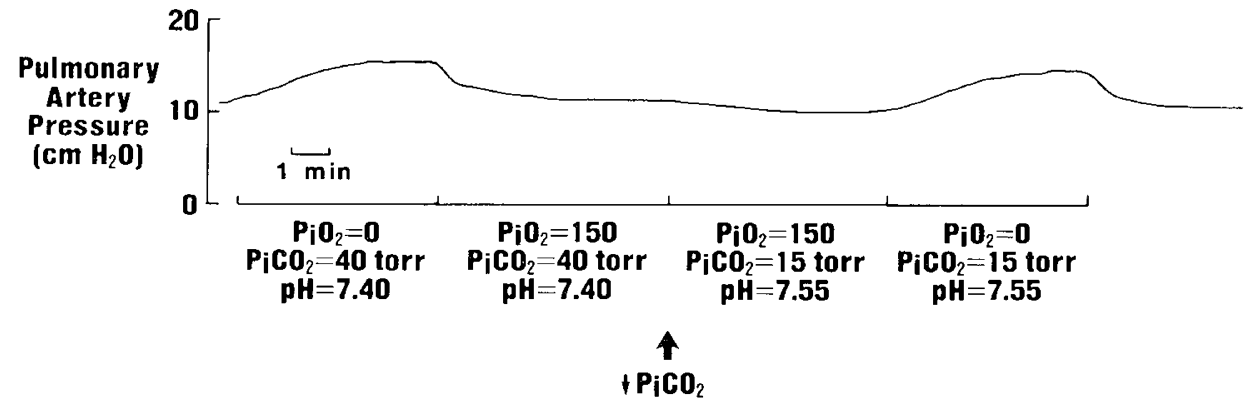

Fig. 2. Typical experiment in which respiratory alkalosis was induced before hypoxia. After hypoxic challenge at $\mathrm{pH}=7.40$, pulmonary arterial pressure returned to baseline. When $\mathrm{Pi}_{\mathrm{CO}_{2}}$ was lowered during normoxia (arrow), pH increased to 7.55 and pulmonary arterial pressure decreased slightly. In response to subsequent hypoxia at $\mathrm{pH}=7.55$, pulmonary arterial pressure increased by a magnitude identical to that observed during exposure to hypoxia at $\mathrm{pH}=7.40$. 
$\mathrm{Pi}_{\mathrm{CO}_{2}}=38-42$ torr). Figure 2 illustrates a typical experiment in which respiratory alkalosis was induced before hypoxia.

Throughout each experiment, we frequently collected blood draining from the left atrial cannula for determination of blood $\mathrm{pH}, \mathrm{P}_{\mathrm{O}_{2}}$, and $\mathrm{P}_{\mathrm{CO}_{2}}$. The duration of perfusion was limited to $2 \mathrm{~h}$ because we previously noted that gross pulmonary edema developed in similar preparations after 3-4 h of perfusion (fluid appeared in the airways and baseline pulmonary airway and arterial pressures increased) (11). At the completion of each study, we examined the trachea for the presence of edema fluid.

Statistics. All data are expressed as the mean \pm SD. For both sequences of exposure to alkalosis and hypoxia, we used a 2-way ANOVA with a Newman-Keuls multiple range test to compare sequential pulmonary arterial pressures. We used $p<0.05$ as an indication of statistical significance (20).

\section{RESULTS}

Values of peak airway pressure were similar for each group and remained constant throughout each study at a mean value of $7.9 \pm 0.9 \mathrm{~cm} \mathrm{H}_{2} \mathrm{O}$. In addition, no edema fluid was seen in the trachea at the completion of any study. Thus, we had no evidence that gross pulmonary edema developed during the length of perfusion.

Before initiating either sequence of exposure to hypoxia and alkalosis, we first demonstrated at least two consistent responses of the pulmonary arterial pressure to alveolar hypoxia. For all lungs, these two responses to hypoxic exposures showed an increase in pulmonary arterial pressure of $46 \pm 20 \%$ and $45 \pm$ $16 \%$.

Table 1 summarizes pulmonary arterial pressures and blood gas values for both sequences of exposure to alkalosis and hypoxia. Baseline values of pulmonary arterial pressure, $\mathrm{pH}, \mathrm{Pa}_{\mathrm{O}}$, and $\mathrm{Pa}_{\mathrm{CO}_{2}}$ were similar for all groups (Table 1). For those groups in which it was measured, the pulmonary arterial pressure returned to the baseline value during ventilation with a normoxic mixture at the end of the study (Table 1). Calculated values of baseline pulmonary vascular resistance (baseline pulmonary arterial pressure - left arterial pressure ( 0 for all these studies) divided by blood flow rate $\left(0.07 \mathrm{~mL} \cdot \mathrm{g}\right.$ body $\mathrm{wt}^{-1} \cdot \mathrm{min}^{-1}$ for all studies) were similar for all groups: $0.14 \pm 0.04,0.18 \pm 0.02$, $0.15 \pm 0.03$, and $0.13 \pm 0.02 \mathrm{~cm} \mathrm{H}_{2} \mathrm{O} \cdot \mathrm{ml}^{-1} \cdot \mathrm{min} \cdot \mathrm{kg}$, respectively for sequence 1 , respiratory alkalosis; sequence 1 , metabolic alkalosis; sequence 2, respiratory alkalosis; and sequence 2, metabolic alkalosis.

Alkalosis during hypoxia. For these experiments (sequence 1 in Table 1 ), values of $\mathrm{pH}$ and $\mathrm{Pa}_{2}$, were similar between respiratory and metabolic alkalosis groups for each step of the se- quence. The values of $\mathrm{PaCO}_{2}$ appropriately reflected the level of $\mathrm{Pi}_{\mathrm{CO}_{2}}$. For both the respiratory and metabolic alkalosis groups, the pulmonary arterial pressure increased from baseline in response to hypoxia at normal $\mathrm{pH}$. When alkalosis was induced during hypoxia, the pulmonary arterial pressure decreased significantly for both the respiratory and metabolic alkalosis groups (Table 1 and Fig. 3). Specifically, the decrease in pulmonary arterial pressure during hypoxia was $18 \pm 16 \%$ when respiratory alkalosis was induced and $17 \pm 7 \%$ when metabolic alkalosis was induced (Fig. 3). Finally, the pulmonary arterial pressure returned to baseline during normoxia.

Alkalosis before hypoxia. For these experiments (sequence 2 in Table 1), values of $\mathrm{pH}$ and $\mathrm{Pa}_{\mathrm{O}_{2}}$ were also similar between

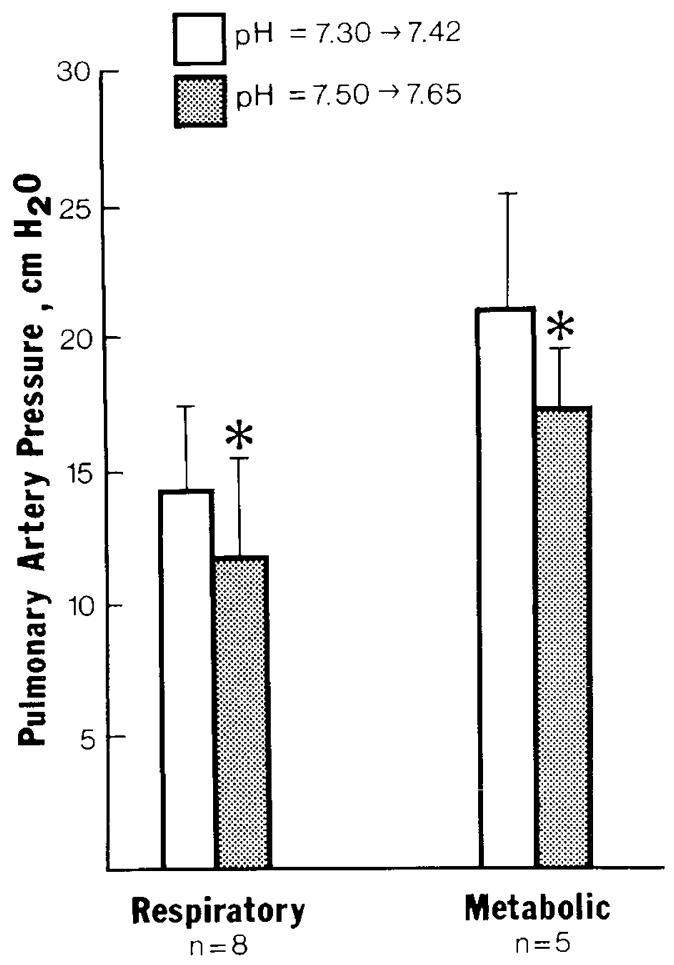

Fig. 3. Pulmonary arterial pressure during hypoxia at $\mathrm{pH}=7.30$ 7.42 and $\mathrm{pH}=7.50-7.65$ for sequence 1 , alkalosis during hypoxia. For both respiratory and metabolic alkalosis studies, pulmonary arterial pressure decreased significantly $\left({ }^{*} p<0.05\right)$ when alkalosis was induced during hypoxia.

Table 1. Sequential pulmonary arterial pressures $(\bar{P} p a)$ and blood gas values for respiratory and metabolic alkalosis groups for sequence $I=$ alkalosis during hypoxia $(n=8$ for respiratory and $n=5$ for metabolic alkalosis) and sequence $2=$ alkalosis before hypoxia $(n=9$ for respiratory and $n=11$ for metabolic alkalosis)*

\begin{tabular}{|c|c|c|c|c|c|c|c|c|}
\hline & \multicolumn{4}{|c|}{ Respiratory } & \multicolumn{4}{|c|}{ Metabolic } \\
\hline & $\overline{\mathrm{P}}$ pa $\mathrm{cm} \mathrm{H} \mathrm{H}_{2} \mathrm{O}$ & $\mathrm{pH}$ & $\mathrm{Pa}_{\mathrm{O}_{2}}$ torr & $\begin{array}{c}\mathrm{PaCO}_{2} \\
\text { torr }\end{array}$ & $\overline{\mathrm{P}}$ pa $\mathrm{cm} \mathrm{H} \mathrm{H}_{2} \mathrm{O}$ & $\mathrm{pH}$ & $\mathrm{Pa}_{2}$ torr & $\begin{array}{c}\mathrm{PaCO}_{2} \\
\text { torr }\end{array}$ \\
\hline \multicolumn{9}{|l|}{ Sequence 1} \\
\hline Baseline & $9.9 \pm 2.4$ & $7.39 \pm .03$ & $149 \pm 10$ & $41 \pm 2$ & $12.6 \pm 1.7$ & $7.40 \pm .03$ & $150 \pm 12$ & $40 \pm 5$ \\
\hline Hypoxia & $14.3+t \pm 3.4$ & $7.39 \pm .04$ & $36 \pm 5$ & $40 \pm 2$ & $21.0 \dagger \pm \pm 4.3$ & $7.39 \pm .04$ & $35 \pm 10$ & $40 \pm 4$ \\
\hline Hypoxia and alkalosis & $11.9+ \pm 3.5$ & $7.59 \pm .05$ & $28 \pm 5$ & $22 \pm 4$ & $17.1+\neq \pm 2.3$ & $7.56 \pm .06$ & $27 \pm 5$ & $40 \pm 5$ \\
\hline Normoxia and alkalosis & $9.0 \div \pm 1.6$ & $7.61 \pm .08$ & $138 \pm 10$ & $20 \pm 2$ & $12.8 \div \pm 1.6$ & $7.57 \pm .05$ & $156 \pm 5$ & $39 \pm 4$ \\
\hline \multicolumn{9}{|l|}{ Sequence 2} \\
\hline Baseline & $10.1 \pm 2.2$ & $7.39 \pm .03$ & $156 \pm 6$ & $41 \pm 2$ & $9.4 \pm 1.8$ & $7.38 \pm .04$ & $157 \pm 5$ & $40 \pm 3$ \\
\hline Hypoxia & $14.5+t \pm 3.4$ & $7.38 \pm .03$ & $34 \pm 2$ & $41 \pm 3$ & $13.0+ \pm \pm 3.2$ & $7.39 \pm .03$ & $32 \pm 4$ & $40 \pm 2$ \\
\hline Normoxia & $10.5 \div \pm 2.4$ & $7.39 \pm .02$ & $157 \pm 7$ & $40 \pm 2$ & $10.1 \ddagger \pm 2.4$ & $7.42 \pm .03$ & $158 \pm 6$ & $39 \pm 3$ \\
\hline Normoxia and alkalosis & $9.3+ \pm 2.1$ & $7.60 \pm .04$ & $153 \pm 7$ & $21 \pm 2$ & $9.1 \pm 2.1$ & $7.55 \pm .03$ & $155 \pm 3$ & $40 \pm 2$ \\
\hline Hypoxia and alkalosis & $13.9+\div \pm 3.4$ & $7.61 \pm .04$ & $32 \pm 3$ & $19 \pm 2$ & $13.3+ \pm 3.9$ & $7.54 \pm .03$ & $32 \pm 5$ & $40 \pm 3$ \\
\hline
\end{tabular}

* All values are mean $\pm \mathrm{SD}$

$\dagger$ Significantly different from baseline.

\$ Significantly different from value immediately preceding. 
respiratory and metabolic alkalosis groups at each step of the sequence. Again, the values of $\mathrm{PaCO}_{2}$ appropriately reflected the level of $\mathrm{Pi}_{\mathrm{CO}_{2}}$. As in the above studies, during hypoxia at normal $\mathrm{pH}$, the pulmonary arterial pressure increased for both the respiratory and metabolic alkalosis groups. After this hypoxic challenge when the lungs were again normoxic, the pulmonary arterial pressure for both the respiratory and metabolic alkalosis groups decreased to the previous baseline level. When alkalosis was then induced during normoxia, the pulmonary arterial pressure decreased by $1.2 \pm 0.7 \mathrm{~cm} \mathrm{H}_{2} \mathrm{O}$ for the respiratory alkalosis studies and by $1.0 \pm 0.8 \mathrm{~cm} \mathrm{H}_{2} \mathrm{O}$ for the metabolic alkalosis studies. Although the magnitudes of these decreases were similar for both groups, the attained pulmonary arterial pressure was significantly less only for the respiratory alkalosis studies. For both groups, the attained levels of pulmonary arterial pressure were not different from the initial baseline pressure. Finally, during hypoxia at the alkalotic $\mathrm{pH}$, the pulmonary arterial pressure increased for both the respiratory and metabolic alkalosis groups. The level of pulmonary arterial pressure during hypoxia at alkalotic $\mathrm{pH}$ was not different than it had been during hypoxia at normal $\mathrm{pH}$. In addition, the magnitude of this increase during hypoxia at alkalotic $\mathrm{pH}$ was the same as it had been during hypoxia at normal pH (Fig. 4). Specifically, for the respiratory alkalosis group, the pulmonary arterial pressure increased by 45 $\pm 8 \%$ during hypoxia at normal $\mathrm{pH}$ and by $46 \pm 12 \%$ during hypoxia at alkalotic pH. Similarly, for the metabolic alkalosis group, pulmonary arterial pressure increased by $38 \pm 12 \%$ at normal $\mathrm{pH}$ and by $45 \pm 8 \%$ at alkalotic $\mathrm{pH}$.

Thus, Figure 3 illustrates that both metabolic and respiratory alkalosis reduced hypoxia-induced pulmonary arterial constriction for the sequence in which alkalosis was induced during hypoxia. In contrast, Figure 4 illustrates that neither metabolic nor respiratory alkalosis reduced hypoxia-induced pulmonary arterial constriction for the sequence in which alkalosis was induced before hypoxia. In other words, the influences of meta-

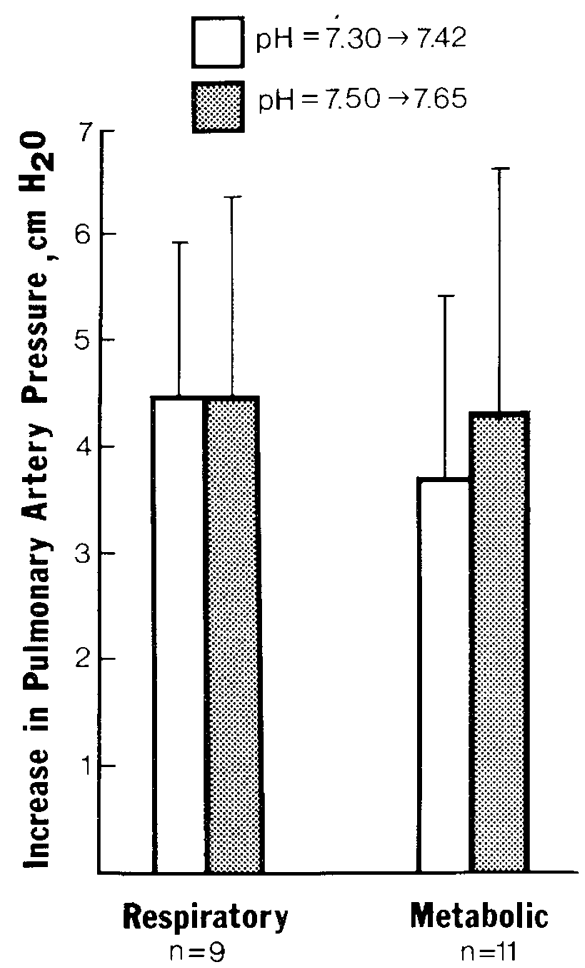

Fig. 4. Increase in pulmonary arterial pressure during hypoxia at $\mathrm{pH}$ $=7.30-7.42$ and $\mathrm{pH}=7.50-7.65$ for sequence 2 , alkalosis before hypoxia. For both the respiratory and metabolic alkalosis studies, the increase in pulmonary arterial pressure during hypoxia was the same at normal and alkalotic $\mathrm{pH}$. bolic and respiratory alkalosis on hypoxic pulmonary vasoconstriction were similar. However, the effect of either mode of alkalosis was different when it was induced during versus before hypoxia.

\section{DISCUSSION}

Most (1, 6-8, 10) but not all (3) studies have reported that alkalosis reduces hypoxia-induced pulmonary vasoconstriction in lungs of mature animals. It is difficult to compare our results in newborn rabbits to those in mature animals because the neonatal and mature pulmonary circulation sometimes have different responses to the same stimuli $(21,22)$. Nonetheless, the few investigators who have used lungs of newborn animals have also reported variable effects of alkalosis on hypoxia pulmonary vasoconstriction (13-15).

Our study in lungs from newborn rabbits may help to explain some of the variability in previous studies in both newborn and mature lungs. Specifically, we found that alkalosis had a different effect on pulmonary vasoconstriction when induced during versus before hypoxia. That is, when we induced alkalosis during hypoxia, pulmonary vasoconstriction was reduced; whereas alkalosis induced before hypoxia had no effect on hypoxic vasoconstriction. Therefore, we suggest that one reason that results varied between previous studies is that different sequences of hypoxia and alkalosis were used in them. For example, investigators using the sequence alkalosis during hypoxia in lungs of mature dogs (7), mature cats (1), and newborn lambs (13) found a reduction in vasoconstriction. In contrast, investigators using the sequence alkalosis before hypoxia found no reduction in hypoxia-induced vasoconstriction in adult humans (3) or newborn calves (14). These results, which were similar to ours, support our idea that the effect of alkalosis on hypoxic vasoconstriction will vary, dependent on the timing of the alkalosis with respect to hypoxia. Furthermore, the results of our study in conjunction with these others lead to two distinct conclusions. The first is that alkalosis reduces ongoing hypoxic pulmonary vasoconstriction. The second is that alkalosis does not blunt the ability of the pulmonary artery to constrict in response to subsequent exposures to hypoxia.

Not all studies support the second conclusion. In particular, some studies found a significant reduction in hypoxic pulmonary vasoconstriction at an alkalotic versus normal $\mathrm{pH}$ when the sequence alkalosis before hypoxia was applied to lungs of mature dogs (6), mature cats (10), mature rats (8), or newborn lambs (15). Differences in species, techniques, and experimental design could contribute to the discrepancies between studies that have used the sequence alkalosis before hypoxia-for example, the time allowed between induction of alkalosis and exposure to hypoxia varied between studies. It is unclear how much time is necessary for $\mathrm{pH}$ to equilibrate between extracellular and intracellular compartments after a decrease in $\mathrm{CO}_{2}$ or an infusion of $\mathrm{NaHCO}_{3}$ (23). Nonetheless, at the time of exposure to hypoxia, the intracellular $\mathrm{pH}$ may have been acidotic in some studies and alkalotic in others. Different intracellular $\mathrm{pH}$ could, thus, have contributed to the variable effect of alkalosis on hypoxic pressor responses. However, the diffusion of $\mathrm{CO}_{2}$ across cell membranes is very rapid (23). It is, therefore, unlikely that differences in equilibration times completely explain why alkalosis blunts subsequent pulmonary vasoconstriction in response to hypoxia in some studies $(6,8,10,15)$ but not in ours and others $(3,14)$.

Another finding in our study was that alkalosis reduced pulmonary arterial pressure during normoxia. Previous investigators have reported similar results $(1,10,13)$. One reason this finding is important is that changes in baseline pulmonary arterial pressure have been shown to alter the magnitude of hypoxic pulmonary vasoconstriction. Specifically, other investigators showed that increases in pulmonary arterial pressure diminished hypoxic vasoconstriction (2). The corollary is that decreases in pulmonary arterial pressure might enhance vasoconstriction in response to 
hypoxia. Thus, one possible reason that alkalosis did not reduce hypoxic pulmonary vasoconstriction for the sequence alkalosis before hypoxia in our study is as follows: a decrease in baseline pulmonary arterial pressure at the alkalotic $\mathrm{pH}$ might have enhanced the ability of the pulmonary artery to constrict in response to hypoxia. This explanation is, however, insufficient because the baseline pulmonary arterial pressure before hypoxia was not significantly less at alkalotic versus normal $\mathrm{pH}$ in our experiments (sequence 2, baseline versus normoxia and alkalosis in Table 1).

In our study, respiratory and metabolic alkalosis had similar effects on pulmonary arterial pressure. This finding implies that increases in $\mathrm{pH}$ and not decreases in $\mathrm{P}_{\mathrm{CO}_{2}}$ are responsible for alkalosis-related decreases in pulmonary arterial pressure. Many investigators have provided evidence to support this conclusion $(6,7,13,15)$. Our additional finding that alkalosis reduced pulmonary arterial pressure during normoxia as well as hypoxia leads to a separate conclusion. That is, either mode of alkalosis might reduce pulmonary arterial pressure at any level of oxygen tension. It should, however, be noted that during normoxia the baseline pulmonary vascular resistance was higher in our isolated lungs of newborn rabbits than has been reported in intact newborns of other species $(13,15)$. Thus, the vasodilatory effect of alkalosis during normoxia might occur only in lungs with elevated pulmonary vascular tone.

The mechanism for alkalosis-related decreases in pulmonary arterial pressure is unclear. Likewise, the mechanism for hypoxic pulmonary vasoconstriction is not known (24). The results of our study do, however, suggest that the mechanisms for these two effects are separate. In other words, the reason that alkalosis acts as a vasodilator during hypoxia is not because alkalosis is blocking the ability of the pulmonary artery to constrict in response to hypoxia. If this were true, then the sequence alkalosis before hypoxia should have resulted in a reduction in hypoxic vasoconstriction, which it did not.

Caution must be used before extrapolating our findings in isolated lungs of newborn rabbits to intact animals. Some of the well-described problems associated with isolated perfused lung preparations are a relatively high total vascular resistance, making it difficult to perfuse lungs at normal in vivo blood flow (25), the tendency to develop edema with prolonged perfusion $(26$, 27 ), and inconsistent responses to hypoxia $(5,6)$. In our experiments, total pulmonary vascular resistance measured in isolated lungs of newborn rabbits was greater than values reported in intact newborn lambs $(13,15)$ but similar to values reported in studies using isolated lungs of newborn lambs $(12,16)$. As indicated by the constant airway pressure throughout and lack of fluid in the trachea at the completion of each study, we had no evidence of gross pulmonary edema in the lungs used in our studies. In this study, we elicited at least two consistent responses to hypoxia at normal pH before inducing alkalosis. We have previously demonstrated that pulmonary arterial pressor responses to hypoxia at normal $\mathrm{pH}$ are reproducible for up to $3 \mathrm{~h}$ of perfusion in isolated lungs from newborn rabbits (11). The magnitude of the pressor response to hypoxia at normal $\mathrm{pH}$ did seem to vary between groups of lungs in this study. Specifically, the hypoxic pressor response at normal $\mathrm{pH}$ appeared to be greater for the respiratory alkalosis group of the sequence alkalosis during hypoxia (sequence 1 in Table 1) than for the other three groups. In addition, the rabbits used for study in the respiratory alkalosis group of sequence 1 tended to be older than the rabbits used for study in the other three groups. We previously showed that the hypoxic pressor response was greater in lungs of 10 - to 14-d-old than 3-to 8-d-old rabbits (11). Other investigators have also found that the magnitude of the pulmonary arterial pressor response to hypoxia varies with postnatal age $(9,16)$. Differences in postnatal ages between groups of animals in this study, therefore, most likely explain differences in hypoxic pressor responses between them.
An additional concern is whether the responses to hypoxia and alkalosis measured in isolated lungs are similar to those in intact animals. Other investigators have demonstrated similar magnitudes of increase in pulmonary arterial pressor in response to hypoxia in isolated lungs of newborn lambs (12) and adult rabbits (9), as compared to intact preparations using the same species $(4,9)$. Thus, we believe our findings in isolated newborn rabbit lungs might represent findings in the living animal. A final concern, however, is that an alveolar $\mathrm{P}_{\mathrm{O}_{2}}$ of 0 torr was used in our studies to achieve elevations in pulmonary arterial pressure in lungs of newborn rabbits. In contrast, newborn infants with the syndrome of persistent pulmonary hypertension have elevated pulmonary arterial pressures despite alveolar $\mathrm{P}_{\mathrm{O}}$, of more than 150 torr. Thus, extreme caution must be used when extrapolating our findings in isolated lungs of newborn rabbits to the clinical situation of an infant with persistent pulmonary hypertension.

In conclusion, with these experimental limitations in mind, our findings in isolated lungs of newborn rabbits indicate that alkalosis might reduce ongoing hypoxic pulmonary vasoconstriction in newborns. Furthermore, either respiratory or metabolic alkalosis could be used to achieve this purpose. However, we must emphasize that our findings suggest that neither mode of alkalosis will prevent subsequent pulmonary vasoconstriction in response to hypoxia.

Acknowledgments. The authors thank M. Giesler and H. Smith for technical assistance and M. Kaplowitz for illustrations.

\section{REFERENCES}

1. Barer GR, McCurric JR. Shaw JW 1971 Effect of changes in blood pH on the vascular resistance of the normal and hypoxic cat lung. Cardiovasc Res 5:490-497

2. Benumof JL, Wahrenbrock EA 1975 Blunted hypoxic pulmonary vasoconstriction by increased lung vascular pressures. J Appl Physiol 38:846-850

3. Bergofsky EH, Lehr DE, Fishman AP 1962 The effect of changes in hydrogen ion concentration on the pulmonary circulation. J Clin Invest 41:1492-1502

4. Bland RD, Bressack MA, Haberkern CM, Hansen TN 1980 L.ung fluid balanee in hypoxic. awake newborn lambs and mature sheep. Biol Neonate 38:221228

5. Hauge A 1968 Conditions governing the pressor response to ventilation hy poxia in isolated perfused rat lungs. Acta Physiol Scand 72:33-44

6. Lloyd TC 1966 Influence of blood $\mathrm{pH}$ on hypoxic pulmonary vasoconstriction. J Appl Physiol 21:358-364

7. Malik AB, Kidd BSL 1973 Independent effects of changes in $\mathrm{H}^{+}$and $\mathrm{CO}$. concentrations on hypoxic pulmonary vasoconstriction. J Appl Physiol 34:318-323

8. Marshall C. Lindgren L, Marshall BE 1984 Metabolic and respiratory hydrogen ion effects on hypoxic pulmonary vasoconstriction. J Appl Physiol 57:545. 550

9. Owen-Thomas JB, Reeves JT 1969 Hypoxia and pulmonary arterial pressure in the rabbit. J Physiol (Lond) 201:665-672

10. Viles PH, Shepherd JT 1968 Relationship between $\mathrm{pH} \mathrm{P}_{\mathrm{O}_{2}}$, and $\mathrm{P}_{\mathrm{CO}_{2}}$ on the pulmonary vascular bed of the cat. Am J Physiol 215:1170-1176

11. Fike CD, Hansen TN 1987 Hypoxic vasoconstriction increases with postnatial age in lungs from ncwborn rabbits. Circ Res 60:297-303

12. Raj JU, Chen P 1986 Micropuncture measurement of microvascular pressures in isolated lamb lungs during hypoxia. Circ Res 59:398-404

13. Schreiber MD. Heymann MA. Soifer SJ 1986 Increased arterial $\mathrm{pH}$, not decreased $\mathrm{PaCO}_{2}$, attenuates hypoxia-induced pulmonary vasoconstruction in newborn lambs. Pediatr Res 20:113-117

14. Silove ED, Inoue T, Grover RF 1968 Comparison of hypoxia. pH and sympathomimetic drugs on bovine pulmonary vasculature. J Appl Physiol 24:355-365

15. Lyrene RK, Welch KA, Godoy G, Philips JB III 1985 Alkalosis attenuates hypoxic pulmonary vasoconstriction in neonatal lambs. Pediatr Res 19:1268-1271

16. Gordon JB, Tod ML, Wetzel RC, McGeady ML, Adkinson NF Jr, Sylvester JT 1988 Age-dependent effects of indomethacin on hypoxic vasoconstriction in neonatal lamb lung. Pediatr Res 23:580-584

17. Drummond WH, Gregory GA. Heymann MA. Phibbs RA 1981 The independent effects of hyperventilation, tolazoline, and dopamine on infants with persistent pulmonary hypertension. J Pediatr 98:603-614

18. Peckham GJ, Fox WW 1978 Physiologic factors affecting pulmonary artery pressure in infants with persistent pulmonary hypertension. J Pediatr 93:1005-1010 
19. West JB, Dollery CT, Naimark A 1964 Distribution of blood flow in isolated lung: relation to vascular and alveolar pressures. J Appl Physiol 19:713-724

20. Zar JH 1974 Biostatistical Analysis. Prentice Hall. Englewood Cliffs, NJ. pp 121-124 and 163-175

21. Cassin S. Tod M. Philips J, Frisinger J, Jordan J. Gibbs C 1981 Effects of prostaglandin $\mathrm{D}_{2}$ on perinatal circulation. Am J Physiol 240(Heart Circ Physiol 9):H755-H760

22. Goetzman BW, Milstein JM 1980 Pulmonary vascular histamine receptors in ncwborn and young lambs. J Appl Physiol 49:380-385

23. Adler S. Roy A, Relman S 1965 Intracellular acid-base regulation: II: the interaction between $\mathrm{C}_{2}$ tension and extracellular bicarbonate in the determination of muscle cell $\mathrm{pH}$. J Clin Invest 44:21-30

24. Fishman AP 1976 Hypoxia on the pulmonary circulation, how and where it acts. Circ Res 38:22l-23

25. Levey S. Gast R 1966 Isolated rat lung preparation. J Appl Physiol 21:313316

26. Fisher AB, Dodia C, Linask J 1980 Perfusate composition and edema formation in isolated rat lungs. Exp Lung Res 1:13-2 15

27. Nicolaysen G 1971 Perfusate qualities and spontaneous edema formation in an isolated perfused lung preparation. Acta Physiol Scand 83:563-570 